\title{
Comunicação
}

[Communication]

\section{Uso de softwares para gerenciamento de rebanhos bovinos leiteiros}

[Use of softwares for the management of dairy cattle]

\author{
M.A. Lopes $^{1}$, A.A. Lago $^{2,4}$, H. Cócaro ${ }^{3,4}$ \\ ${ }^{1}$ Departamento de Medicina Veterinária - UFLA \\ Caixa postal 3037 \\ 37200-000 - Lavras, MG \\ ${ }^{2}$ Aluna de graduação - UFLA - Lavras, MG \\ ${ }^{3}$ Aluno de pós-graduação - UFLA - Lavras, MG \\ ${ }^{4}$ Bolsista do CNPq
}

Os microcomputadores começaram a ser usados na agricultura na década de 60 , mediante técnicas de programação linear, utilizada para determinação de custos para rações animais e no planejamento de uso de máquinas agrícolas (Moverley, 1986). Constata-se que a informatização das empresas rurais iniciou-se com o uso de programas em tarefas administrativas. Somente levantamentos mais recentes apontam a utilização de outros tipos de programas, como os de controle de produção animal e os de planejamento (Rezende, 1998).

Sistemas computadorizados de informação são considerados ferramenta importante no monitoramento de rebanhos, pois permitem o melhor controle desses por intermédio do fluxo continuo de informações. Essas informações favorecem a tomada de decisões, permitem reduzir custos e, como conseqüência, aumentam o desempenho dos rebanhos (Lopes, 1997).

Barbosa et al. (2000) salientaram que é comum aos produtores encontrarem dificuldades de gerenciamento de rebanho, pelo fato de os softwares não corresponderem às suas expectativas. Vale e Rezende (1999) também enfatizaram a necessidade de se conhecer $o$ estado atual da utilização de sistemas computacionais dentro das propriedades rurais e do nível de satisfação do usuário com a adoção dessa tecnologia, seu perfil e suas necessidades.

Recebido em 14 de junho de 2005 Aceito em 20 de fevereiro de 2007 E-mail: malopes@ufla.br
O objetivo desta pesquisa foi investigar se os softwares para gerenciamento de rebanho bovino leiteiro disponíveis no mercado têm atendido as expectativas dos produtores rurais.

Este trabalho consistiu em uma pesquisa realizada junto aos pecuaristas que utilizam a informática para gerenciar o rebanho bovino leiteiro. Utilizou-se um questionário qualitativo semi-estruturado contendo 49 questões, sendo 46 de múltipla escolha e três questões abertas, para avaliar o uso de softwares para gerenciamento de rebanhos bovinos leiteiros. Para a elaboração dos questionários, tomaram-se como referência os trabalhos de Cócaro (2004) e Barbosa (1999).

A pesquisa foi realizada com participantes da $13^{\mathrm{a}}$ Exposição Nacional da Pecuária Leiteira, em 2004, em São Paulo. Responderam ao questionário apenas os pecuaristas que utilizam softwares específicos para agropecuária, pecuaristas que utilizam pacotes aplicativos (softwares básicos), tais como Word, Excel e Access e aqueles que desenvolveram um software personalizado. As respostas obtidas foram analisadas por meio de estatísticas descritivas e, portanto, não estão sujeitas a generalizações.

Foram abordados 35 pecuaristas, sendo que 23 (66\%) utilizavam a informática para o gerenciamento do rebanho, e 12 (34\%) não a utilizavam. Os resultados e discussões referem-se apenas aos 23 citados acima. 
O uso de softwares específicos é grande entre os produtores, pois 15 deles $(66 \%)$ os utilizam exclusivamente para gerenciar o rebanho, 4 (17\%) utilizam somente softwares básicos, tais como Word, Excel e Access, e 4 (17\%) utilizam ambos os tipos de softwares. O tempo médio de uso do computador por esses produtores é de cinco anos, nove meses e 18 dias. Os controles (registros) e monitoramentos mais utilizados foram: controle reprodutivo, sanitário, controle leiteiro e avaliações econômicas e financeiras.

A administração da empresa é realizada em $74 \%$ dos casos pelos proprietários e em $26 \%$ por um funcionário. A maioria dos produtores relatou morar na cidade (74\%). Isso permite destacar o potencial papel dos softwares para acompanhamento da atividade, uma vez que os relatórios emitidos podem retratar a situação do sistema de produção, auxiliando os pecuaristas a tomarem decisões, mesmo estando distantes da propriedade. Observou-se que quem está mais familiarizado com a informática é o administrador (52\%), seguido pelo proprietário (35\%), por um funcionário $(30 \%)$ e, por último, alguém da família (17\%).

A maioria dos pecuaristas não teve necessidade de contratar ou dispensar mão-de-obra com a implantação do software, sendo que $83 \%$ dos entrevistados responderam que o número de funcionários se manteve o mesmo, $13 \%$ disseram que a empresa teve necessidade de contratar mais funcionários e $4 \%$ que houve necessidade de dispensa de mão-de-obra. A não necessidade de contratação de mão-de-obra também pode ser justificada analisando-se quem é o responsável pela digitação dos dados. Em $67 \%$ dos casos, o responsável é o próprio produtor e apenas em $33 \%$ essa tarefa é realizada por funcionários como o gerente, o empregado ou o técnico.

Sabe-se que apenas a adoção de um software não garante que seu uso seja eficiente, por isso, o treinamento específico é fundamental para se obter bons resultados (Freitas e Liberalli Neto, 1995). A maioria dos produtores (74\%) não ofereceu treinamento na área de informática aos seus funcionários, e apenas $26 \%$ assim o fizeram. Entre esses, $67 \%$ foram treinados fora da propriedade e $33 \%$ foram treinados na propriedade.
$\mathrm{O}$ uso do software específico atendeu às expectativas dos produtores, pois 21 deles (91\%) responderam estarem satisfeitos com o sistema, $\mathrm{e}$ apenas $2(9 \%)$ responderam não. Entre essas expectativas foram citadas: melhora do controle zootécnico, da eficiência do rebanho, da gestão dos recursos produtivos e do controle administrativo. Os não satisfeitos reclamaram que o software não atendeu a todas as rotinas necessárias, havendo necessidade de utilizar softwares básicos.

Foi possível perceber a importância dos relatórios na organização e na realização das tarefas dentro da empresa. Cerca de $80 \%$ dos produtores imprimiram relatórios para realização de tarefas com o nome dos responsáveis. Destes, $33 \%$ o fizeram semanalmente, $28 \%$, quinzenalmente, e $39 \%$, mensalmente. Apenas $22 \%$ dos pecuaristas não utilizaram relatórios, repassando as tarefas verbalmente ou por escrito. Os relatórios mais utilizados são de análises de custos (43\%) e zootécnicos (70\%), o que evidencia a maior preocupação com esses aspectos.

A importância do controle de estoques e relatórios que possibilitem seu inventário exato é fundamental para o planejamento de compras da empresa e para a determinação exata do custo da atividade (Brito e Brito, 1999). Entretanto, 74\% dos pecuaristas informatizados alegaram que $o$ software não possui programas para controlar a compra e o uso de insumos, $17 \%$ responderam que o software atende a essa função e $9 \%$ desconhecem essa informação. Sabe-se da dificuldade das empresas rurais em controlar seus estoques de insumos, contudo, os sistemas de informação têm condições de auxiliá-las. Por isso, é fundamental que esse tipo de rotina seja incorporado aos sistemas pelas empresas que desenvolvem softwares para pecuária.

Para $87 \%$ dos entrevistados não houve dificuldade na coleta de dados a serem inseridos no software, e $13 \%$ responderam que tiveram dificuldades. Dentre essas dificuldades destacaram-se a movimentação de animais (67\%) e a perda de dados pelos funcionários no momento da coleta (33\%).

Uma das soluções encontradas para minimizar essa perda é o treinamento dos funcionários para coleta de dados, pois isso contribui para melhorar 
a confiabilidade das informações geradas pelo software. Os resultados apontaram que 13 (57\%) dos funcionários não foram treinados, e apenas $10(43 \%)$ receberam treinamento. Os motivos apresentados pelos produtores foram: 0 funcionário julgou-se capacitado para a tarefa, seis respostas; o funcionário não tem capacitação para receber o treinamento, cinco respostas; e não há quem o capacitasse, duas respostas. Para os produtores que ofereceram treinamento aos seus funcionários, os resultados foram satisfatórios e atenderam às expectativas.
Assim, na opinião dos produtores, os critérios mais importantes para um software ser útil na tomada de decisão são os resultados proporcionados e a qualidade das informações. Em geral, os resultados mostraram que o uso de software específico atende às expectativas do usuário.

Palavras-chave: bovinocultura de leite, informática, monitoramento de rebanhos

\begin{abstract}
The softwares for the management of dairy herd available in the market were studied considering the expectations of the rural producer. Twenty-three farmers whose properties were computerized were interviewed. It was used a qualitative semi-structured questionnaire containing 49 questions: 46 of them were multiple choice and 3 open ones. The proportionate results and the quality of the information were the most important criteria for specific software in helping the administrative decisions. In spite of the training, so much for data collection as for the use of the softwares, it was little valued by the producers. The results showed that the use of these systems is fitting the expectations of the user especially in the zootechnic and administrative areas.
\end{abstract}

Keywords: dairy cattle, computer science, monitoring of herd

\section{REFERÊNCIAS BIBLIOGRÁFICAS}

BRITO, M.J.; BRITO, V.G.P. Gestão de recursos materiais. 1999. 79f. Monografia (Especialização em Administração Rural) Universidade Federal de Lavras, Lavras, MG.

BARBOSA, M.P. Software para gerenciamento de rebanhos bovinos: desenvolvimento $e$ avaliação pela softhouse e seleção e avaliação pelo pecuarista. 1999. 48f. Monografia (Especialização em Administração Rural) Universidade Federal de Lavras, Lavras, MG.

BARBOSA, M.P.; LOPES, M.A.; ZAMBALDE, A.L. Software para gerenciamento de rebanhos bovinos: desenvolvimento e avaliação pela softhouse. Rev. Bras. Agroinf., v.3, p.13-20, 2000.

CÓCARO, H., Avaliação do uso de softwares para gerenciamento de rebanhos bovinos leiteiros no sul de Minas Gerais: um estudo de caso. 2004. 51f Monografia (Especialização em Administração Rural) - Universidade Federal de Lavras, Lavras, MG.

FREITAS, H. M. R; LIBERALLI NETO, G. Um estudo sobre a integração da tecnologia da informação à gerência e administração de fazendas agropecuárias. In: AGROSOFT 95 SEMINÁRIO INTERNACIONAL DE INFORMATIZAÇÃO DA AGROPECUÁRIA, 1995, Juiz de Fora. Anais... Juiz de Fora: Softex 2000, 1995. 1 CD-ROM.

LOPES, M.A. Informática aplicada a bovinocultura. Jaboticabal: FUNEP, 1997. 82p.

MOVERLEY, J. Microcomputers in agriculture. London: Collins Professional and Technical Books, 1986. p.219.

REZENDE, M.L. O uso da informática na Agropecuária: o caso dos suinocultores da Zona da Mata de Minas Gerais. 1998. 93f. Dissertação (Mestrado) - Universidade Federal deViçosa, Viçosa, MG

VALE, S.M.L.R.; REZENDE, M.L. Uso da informática na Agricultura Mineira: Perfil do usuário e Estado da Arte. In: AGROSOFT 99 FEIRA E CONGRESSO DE INFORMÁTICA APLICADA À AGROPECUÁRIA E AGROINDÚSTRIA, 1999, Juiz de Fora. Anais... Juiz de Fora: Softex 2000, 1999. 1 CD-Rom. 